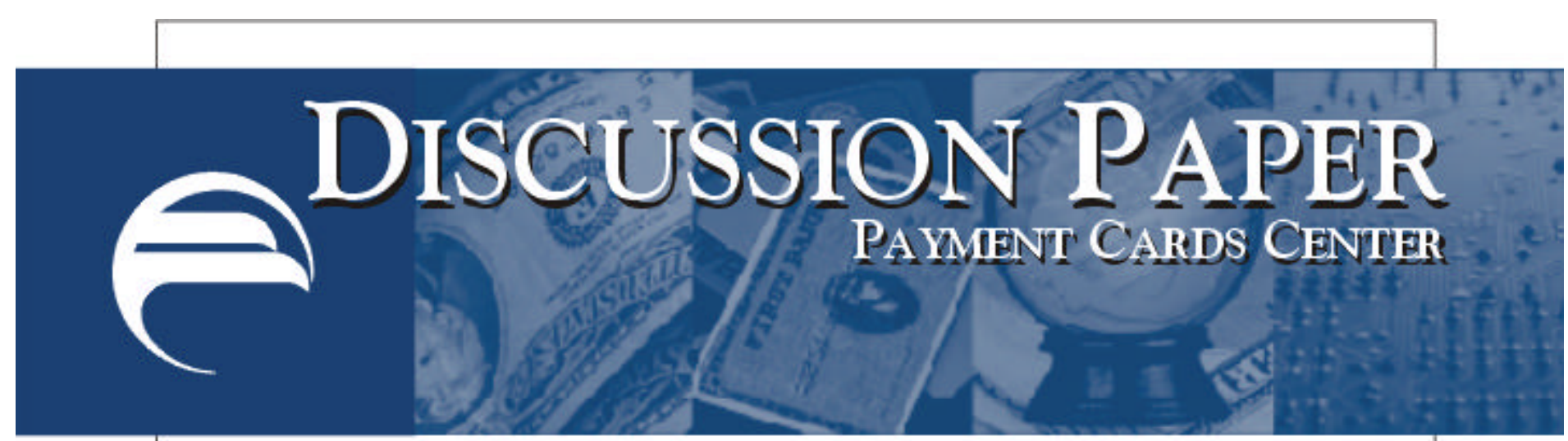

\title{
A Panel Discussion on Dynamics In the Consumer Credit Counseling Service Industry*
}

\author{
Anne Stanley
}

September 2001

Summary: On July 20, 2001 the Payment Cards Center of the Federal Reserve Bank of Philadelphia sponsored a workshop on the consumer credit counseling service industry. Leading the moderated discussion were four senior executives from regional credit counseling firms associated with the National Foundation for Credit Counseling (NFCC). Jerome Johnson, president and CEO and Ghyll Theurer, program manager represented the Consumer Credit Counseling Service (CCCS) of South Jersey, a program of Family Service Association. James Godfrey, executive vice president, Consumer Credit Counseling Service (CCCS) of Maryland and Delaware, Inc. and Patricia Hasson, president of Consumer Credit Counseling Service (CCCS) of Delaware Valley, Inc. rounded out the panel. The discussions were enriched by the breadth of experiences represented by the panelists who come from a variety of industry and nonprofit backgrounds. The panel discussed the role of credit counseling firms mediating between financially troubled consumers and their unsecured credit card lenders. This paper is a summary of those discussions.

*The views expressed here are not necessarily those of this Reserve Bank or of the Federal Reserve System.

\section{Federal Reserve Bank of Philadelphia}




\section{Background \& History}

Jerome Johnson opened the discussion with some background and history of the NFCC; he also described the industry's economic structure. The NFCC, which was founded in 1951, is the nation's oldest and largest non-profit organization dedicated to budget and credit education and counseling. NFCC member agencies, many of which operate under the name Consumer Credit Counseling Service (CCCS) are non-profit organizations that provide consumers with confidential money management, homeowner counseling and educational services. CCCS agencies are independently accredited by the Council on Accreditation of Services for Familes and Children Inc. (COA). COA accreditation identifies organizations in which consumers can have confidence, protects organizations against lowering standards, enables organizations to meet measurement and reporting requirements and demonstrates accountability in the management of resources. In addition, CCCS agencies require that all counselors employed by them undertake the professional preparation to become certified consumer credit counselors. There are approximately 175 NFCC affiliated counseling agencies with some 1,418 offices throughout the United States, Puerto Rico and Canada.

According to the NFCC's web site members provided counseling to 1.6 million families in 1999, helping many to take control of their finances. Budget counseling allowed one third of their clients to repay their debts on their own. Only 7 percent were referred to an attorney for legal assistance to begin the process of filing bankruptcy. Another 33 percent of consumers receiving counseling entered debt management plans. Debt management plans are contracts between the consumer and creditor, using a credit counseling agency as the liaison between them. The agencies negotiate repayment terms 
with creditors on behalf of their clients, and clients agree to make monthly payments to the agency, which in turn, remits a proportional share to all the unsecured creditors. In working with their clients, the CCCS agencies work toward a goal of having the client debt-free within five years of beginning a plan.

The success of these programs is evident in the numbers: in 2000 , some $\$ 5$ billion dollars was repaid to creditors (primarily credit card issuers) under CCCS debt management plans. This total does not include the one third of their clients who receive only budget counseling, most of whom presumably remain current with their debt obligations. Mr. Johnson emphasized in rendering this service, credit counseling agencies can often be seen as an alternative to bankruptcy for financially constrained consumers and clearly a benefit to creditors. In fact, this mutually supportive structure and the underlying trust between creditor companies and the CCCS agencies was said to have characterized the relationships for most of the recent past. Some of that is changing, as described below.

CCCS agencies depend heavily on contributions from creditors in return for the money recovered. This is typically a percentage of the payment made to the creditor under a debt management plan and then given back to the agency, commonly referred to as "fair share." Using 1999 figures, Mr. Johnson pointed out that while "fair share" payments are received for only the 35 percent of CCCS clients who enter debt management plans, this primary revenue source must cover expenses associated with the agencies' broader education and counseling activities. "Fair share" reimbursements are negotiated by NFCC at the national level with the major credit card issuers and historically they were close to 15 percent of amounts collected. More recently, these 
negotiated contribution levels have decreased substantially, to the 7 to 10 percent range, placing significant financial strains on the CCCS agencies.

\section{Changes in the Market}

Ghyll Theurer and James Godfrey led the discussion on the next topic: the changing dynamics which have led to these lower reimbursement rates and other changes in the relationships between CCCS and the creditors they service. A significant factor has been the changing structure and explosive growth in the counseling industry. While the NFCC and its affiliated agencies essentially defined the industry for many years, Ms. Theurer noted the rapid growth of new agencies outside of the NFCC frame over the past decade and the fact that many of these new alternative agencies may be operating on a for-profit basis. Mr. Godfrey noted that in 1990, of the 225 credit counseling agencies in the U.S., 202 were affiliated with NFCC. In 2000, the total number had grown almost four- fold to over 800 agencies, only 175 of which were affiliated with NFCC.

The new entrants in the market were described as more profit oriented than the traditional CCCS agencies, which operate with a broader educational mission. The new entrants also tend to be more efficient and technologically advanced. Many focus exclusively on debt management plans, aggressively advertising their services to prospective clients, offering only telephone counseling and willing to negotiate reduced "fair share" contributions with issuers. While there are clearly highly professional operations among the new industry entrants, the publicized "debt mills" and other less professional organizations also fall within this category.

According to Mr. Godfrey, since 1993, the number of debt management plans entered into by consumers has increased tenfold. This, of course, has meant that creditors 
pay more money in the form of "fair share" contributions. The panelists generally agreed with the industry's contention that a number of those attempting to enter debt management plans do not qualify and would likely be able to manage their financial obligations without concessions. The industry's reaction has been not only to lower the level of payments to the credit counseling agencies but also to heavily scrutinize all applicants for debt management plans and tighten concession terms. In brief, the historic level of trust between creditors and counseling services has been eroded, increasing costs to both parties.

In response to questions, the panelists also touched on the impact of the wave of consolidation passing through the credit card industry. Greater industry concentration means fewer creditors with which to negotiate, but there was some sense that these "mega creditors" exercise more leverage in the negotiations. For credit counseling agencies operating problems abound: keeping track of changing account numbers and other client information following mergers is often a significant challenge. Ms. Theurer observed that, in some cases, consumers currently in debt management plans with a creditor that merges find the new lender wants to change the terms and conditions of the previous agreements. Both agencies and consumers are then faced with the lengthy process of renegotiating a plan with the new creditor and all that entails.

One positive development that has arisen from the heightened competition and industry restructuring is that the original CCCS agencies have had to examine their business models and focus on improving productivity. The panelists agreed that to a certain extent the agencies had become complacent and were slow to adopt new technologies to improve service levels to consumer clients and creditors. Some agencies 
are experimenting with creating fee structures that require the consumer clients to share at least a modest part of the costs and hopefully also introduce compliance incentives.

\section{The Impact of Bankruptcy Reform Legislation}

The concluding section of the workshop was led by Patricia Hasson, president of the CCCS of Delaware Valley, who shared her views on the potential impact of the proposed new bankruptcy legislation currently being debated in Congress. The current version of the bill would require petitioners to obtain a "certificate" of contact with a nonprofit credit counseling service prior to filing for bankruptcy. Then, the consumer would have to complete a financial-education course before the bankruptcy would be discharged. These provisions would have the most immediate impact on credit counseling agencies. At this stage no one knows what will be required in these areas, how such actions would be administered, or how the service providers would be compensated.

Despite these uncertainties, the legislation may provide consumer credit counseling services an opportunity to play a more proactive role. Ms. Hasson emphasized that much would depend on what is meant by financial education and how the certification process would work. If the certification process provides some incentive to structure a debt management plan as an alternative to filing for bankruptcy, it could lead to more opportunities for the agencies and potentially lower the level of filings. Similarly, given their historic role in providing financial education, the CCCS agencies would seem well positioned to participate in this aspect of the bill's requirements. At the same time, agencies will most likely need to examine their financial-education models to make sure they satisfy the higher demand in ways that are effective and cost efficient. 